\title{
An Immunohistochemistry-Based Study on Aquaporin (AQP)-1, 3, 4, 5 and 8 in the Parotid Glands, Submandibular Glands and Sublingual Glands of Sjögren's Syndrome Mouse Models Chronically Administered Cevimeline
}

\author{
MORIYOSHI NAKAMURA*,**, TSUYOSHI SAGA*, KOICHI WATANABE*, \\ NAGAHIRO TAKAHASHI*,†, YOKO TABIRA*, JINGO KUSUKAWA** \\ AND KOH-ICHI YAMAKI* \\ *Department of Anatomy, **Dental and Oral Medical Center, and ${ }^{\dagger}$ Department of Plastic, \\ Reconstructive and Maxillofacial, Kurume University School of Medicine, \\ Kurume 830-0011, Japan
}

Received 28 December 2012, accepted 7 May 2013

J-STAGE advance publication 7 August 2013

\begin{abstract}
Summary: Cevimeline is a muscarinic agonist that promotes saliva secretion and is used to treat Sjögren's syndrome (SS), an autoimmune disorder in which the exocrine glands that produce saliva are destroyed. Cevimeline is thought to affect the composition of saliva in part by regulating the localization of aquaporins (AQPs). In this study, we investigated the effects of chronic Cevimeline administration in the salivary glands of SS mice on the immunohistochemical localization of aquaporin (AQP)-1, 3, 4, 5 and 8.

We used Cevimeline-untreated SS mice, treated SS mice, discontinued SS mice and untreated normal mice.

AQP-5 was found in the apical and lateral membranes of acinar cells in the parotid and submandibular glands of cevimeline-treated SS mice and untreated normal mice. Saliva secretion and AQP-5 localization were sustained in SS mice who were chronically administered Cevimeline and at four weeks after discontinuation. Unlike AQP-5, the localization of AQP-1, 3, 4 and 8 were not affected by Cevimeline administration.

Our findings demonstrated that administration of Cevimeline maintains the proper localization of AQP-5 in the acinar cells of the salivary gland, which may promote salivation in chronically treated SS mice. Clinically, this suggests that chronic Cevimeline administration may be useful therapeutically for SS patients suffering from a decrease in saliva secretion by improving the disordered AQP-5 localization.
\end{abstract}

Key words aquaporine, Cevimeline, Sjögren's syndrome, SS mice, parotid glands, submandibular glands

\section{INTRODUCTION}

The salivary glands keep the mouth and body healthy, producing saliva that contains mucosal fluids such as mucin, various kinds of digestive enzymes, and IgA. Xerostomia can lead to dental caries, the advancement of periodontal disease, taste disorders and morphological abnormalities seen in chronic inflammation of the oral mucosa, as well as various types of discomfort such as dry mouth, slimy mouth and bad breath. Systematic disease or metabolic problems such as diabetes, kidney damage and anemia, mental conditions such as depression and stress, drug problems such as anxiolytic and depressor drugs, and functional disorders of the salivary glands cause these discomforts. Saliva secretion is a major symptom of functional disorders of the salivary glands, as typified by Sjögren's syndrome (SS) [1]. SS is an autoimmune disorder caused by chronic inflammation of exocrine glands such as the salivary glands and lacrimal glands, 
causing basic lesions [2].

Cevimeline is a muscarinic receptor agonist that was jointly developed by the Israel Institute for Biological Research and Snow Brand Milk Products Co., Ltd. Cevimeline acts by stimulating the M3 muscarinic receptor [3], G protein activating phospholipase $\mathrm{C}$, to release $\mathrm{Ca}^{2+}$ inside the endoplasmic reticulum. The released $\mathrm{Ca}^{2+}$ acts on cell membranes to secrete electrolytes inside the glandular cavity. Original saliva is produced in accordance with the generated osmotic pressure gradient. Cevimeline is widely used clinically in SS patients to accelerate saliva secretion $[4,5]$. It has been reported that the effect of salivary secretion continues with long-term internal use of Cevimeline in SS patients [6].

Furthermore, Yakeishi et al. [7] reported a Cevimeline-induced decrease in secretory granules inside the acinar cells, an increase in rough endoplasmic reticulum, expansion of intercellular spaces and appearance of the condensing vacuoles of the Golgi apparatus. This was based on the observation of morphological transformation of the submandibular glands in a mouse model of SS following the administration of Cevimeline, thus demonstrating the results of secondary acceleration of saliva secretion [7].

Aquaporins (AQPs) are six-transmembrane proteins that play an important role in the water transport of cell membranes in plants and animals $[8,9]$. To date, 13 types of AQPs have been confirmed (AQP-0 to AQP-12). It has been suggested so far that AQP-1, $3,4,5$ and 8 exist in the salivary glands of humans and rodents [10-12]. It has been reported that AQP-5 is largely involved in water transport during saliva secretion in the salivary glands $[13,14]$. Previously Yakeishi et al. [7] reported the relocalization of AQP-5 to the apical membrane of acinar cells in the submandibular glands of SS mice after administration of Cevimeline [7]. They also saw a significant decrease in secretory granules inside the acinar cells of the submandibular glands. Furthermore, in SS mice not administered Cevimeline, AQP-5 mislocalized to the basolateral membrane of acinar cells in the submandibular glands and there was an increase in the secretory granules of acinar cells in the submandibular glands. This indicated that the administration of Cevimeline potentially improves the localization of AQP-5 in addition to promoting salivary secretion in SS mice [7].

However, the effects of chronic administration of Cevimeline or its discontinuation on the localization of AQP-5 have not yet been clarified. To this end, we used SS mice as a model to verify changes in localization of AQP-5 following chronic administration and discontinuation of Cevimeline.

In this study, the localization of AQP-5 was shown by immunohistochemistry. AQP-5 was found to be mainly related to saliva secretion, whereas the localization of AQP-1, 3, 4 and 8 is thought to affect saliva composition. The relationship between the localization of AQP-5, using MRL/MpJ-Tnfrsf6 ${ }^{\mathrm{lp} / \mathrm{Crlj}}$ (MRL/l) mice [15-18] that naturally develop symptoms of sialadenitis or angiitis was also shown. We conducted a histological study on the inflammatory changes in the salivary gland tissues of the salivary glands of 4 groups: a group of SS mice not administered Cevimeline, a group of SS mice administrated Cevimeline, a group of SS mice chronically administered Cevimeline, a group that received but then discontinued Cevimeline, and a group of normal mice not administered Cevimeline.

\section{MATERIALS AND METHODS}

\section{Experimental animals (Fig. 1)}

Twenty-seven 9-week-old MRL/l male mice (Japan SLC, Inc., JPN) were used as SS mouse models and ten 9-week-old normal BALB/cN male (Kyudo Co., Ltd., JPN) mice were purchased for use as controls. SS mice were divided into three groups, a group of 8 mice that was not administered Cevimeline, a group of sixteen mice administered Cevimeline, and a group of three mice that received but then discontinued Cevimeline. They were fed solid feed freely inside breeding cages with a $12 \mathrm{~h}$ light and dark cycle. Cevimeline hydrochloride hydrate (Nippon Kayaku Co., Ltd., JPN) was administered at approximately 4 $\mathrm{mg} / \mathrm{kg}$, based on approximately $5 \mathrm{ml} /$ day water intake per mouse. Two-hundred $\mathrm{ml}$ of tap water, into which 4 $\mathrm{mg}$ of Cevimeline was mixed and poured into water drinking bottles, was given to the Cevimeline groups, including those that would then discontinue the drug. For the discontinuation group, discontinuation began after the 7th week of administration. Drug-free tap water was given to the non-administration group. We changed the water twice a week, and checked that a sufficient amount had been consumed. Normal mice were housed inside breeding cages and fed solid feed; tap water was freely available with no dissolution of drugs, for a period of 1 week. Salivary glands were collected every 2 weeks from the 10th week after birth from the SS mice not administered Cevimeline and SS mice administered Cevimeline. Salivary glands were collected at the second and fourth week of discontinuation from the SS mice discontinuing Cevimeline. Salivary glands were collected at the 10th week from 


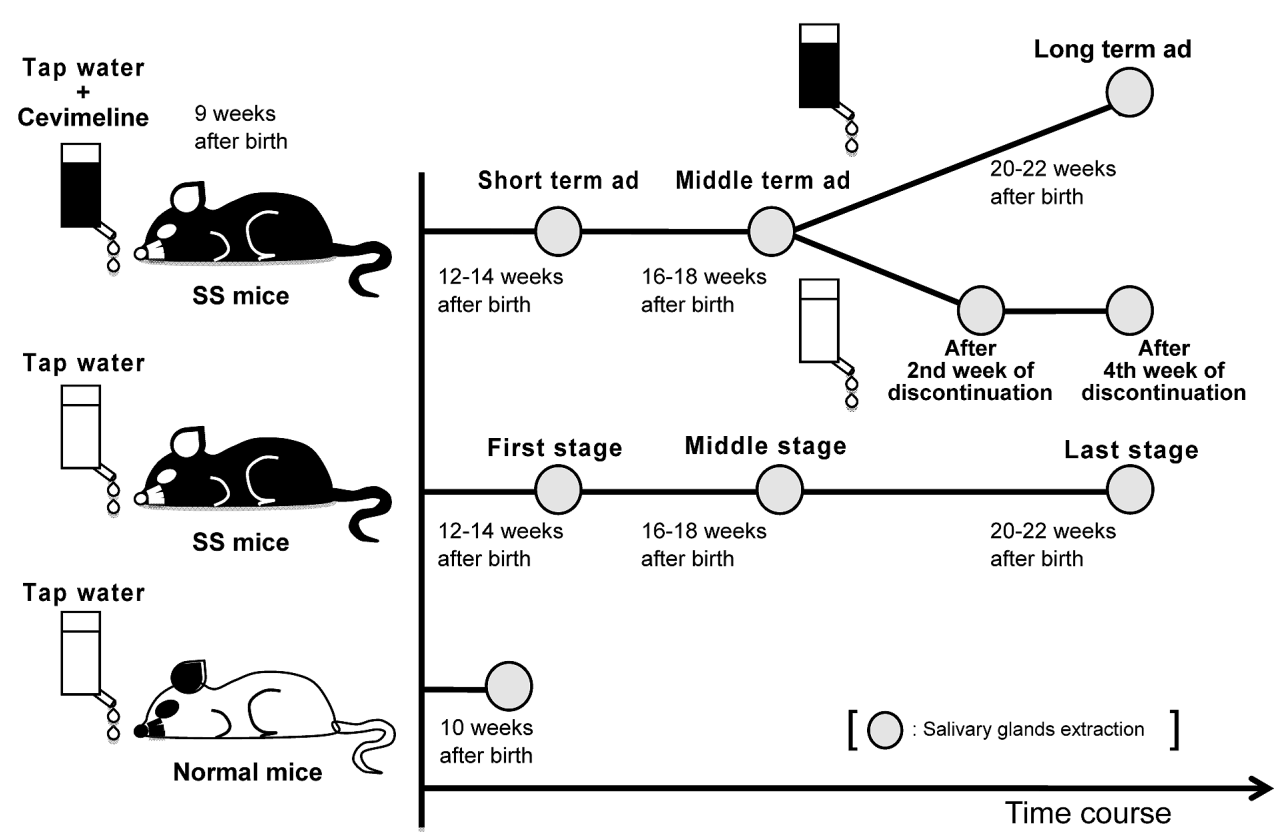

Fig. 1. Schematic diagram of animal groups in this study.

Cevimeline-untreated SS mice, treated SS mice, discontinued SS mice and untreated normal mice were used. SS mice were classified into 3 groups according to the term of administretion. Discontinued SS mice were classified into 2 groups according to the term of discontinuation. Salivary glands (parotid, submandibular and sublingual gland) were extracted at each term.

normal mice as a control. Each mouse was deeply anesthetized using diethyl ether and their salivary glands were collected following immobilization using a 2.0\% paraformaldehyde $/ 2.5 \%$ glutaraldehyde PBS solution perfused via the heart after celiotomy.

SS mice administered Cevimeline were classified into administration periods. Short-term administration (Short-term ad) refer to 3-5 weeks after administration (12-14 weeks after birth),

Middle-term administration (Middle-term ad) refer to 7-9 weeks after administration (16-18 weeks after birth), and Long-term administration (Long-term ad) refer to 11-13 weeks after administration (20-22 weeks after birth). The SS mice not administered Cevimeline were classified in accordance with the timing after birth of Cevimeline administration in the group receiving Cevimeline. First stage refers to 1214 weeks after birth, Middle stage refers to $16-18$ weeks after birth, and Last stage refers to 20-22 weeks after birth.

This experiment and the experimental animals were properly treated and controlled, as authorized by the Animal Research Committee of Kurume University.

\section{Tissue preparation}

The parotid, submandibular, and sublingual glands from both normal and SS mice were fixed in Bouin's fluid for more than $24 \mathrm{~h}$ for immunohistochemistry. After fixation, the salivary glands were embedded in paraffin and serially sectioned at a thickness of $5 \mu \mathrm{m}$. Sections were stained with H\&E and AQP-1, 3, 4, 5 and 8 antibody.

\section{Immunohistochemical staining}

Immunohistochemical staining was performed on SS mice not administered Cevimeline, on SS mice administered Cevimeline, and on normal mice. The tissues were deparaffinized and endogenous peroxidase was blocked with $3 \% \mathrm{H}_{2} \mathrm{O}_{2}$ /methanol solution. Next, $10 \%$ normal goat serum was used as a blocking reagent to prevent nonspecific antibody reactions. Polyclonal antibodies AQP-1 (Santa Cruz Biochnologt, Inc., USA), AQP-3 (Santa Cruz Biochnologt, Inc., USA), AQP-4 (Santa Cruz Biochnologt, Inc., USA), AQP-5 (Alomone Labs Ltd., Israel) and AQP-8 (Santa Cruz Biochnologt, Inc., USA) were used as the primary antibody. Only the AQP-5 polyclonal antibody was used for the SS mice discontinuing Cevimeline. The primary antibody was incubated overnight (approximately $15 \mathrm{~h}$ ), and then incubated with biotinconjugated anti-rabbit IgG secondary antibody before being incubated with the peroxidase-conjugated strepta- 
vidin as the enzyme reagent. Subsequently, staining was carried out with $0.05 \%$ DAB-Tris buffer solution with $0.03 \% \mathrm{H}_{2} \mathrm{O}_{2}$, and the nucleus was stained using VECTASHIELD Mounting medium with DAPI (Vector Laboratories, Inc., USA) as a mounting agent.

Multi-color staining was performed by the concomitant use of the enzyme- and fluorophore-conjugated antibodies, using a polyclonal anti-AQP-5 and anti-occludin antibodies (Santa Cruz Biotechnology, Inc., USA). Each parotid gland was stained 10 weeks after birth for the Cevimeline-treated SS mice, untreated SS mice, and untreated normal mice. First, AQP-5 was stained with $\mathrm{DAB}$, occludin was stained using Alexa fluor 568 (Molecular Probes, Inc., OR)-conjugated anti-rabbit IgG antibody, and the nucleus was stained with DAPI.

\section{Image analysis of $A Q P-5$}

ImageJ (free image processing software developed by the National Institute of Health) was used to quantify AQP-5 localization. AQP-5 was quantified using tissue images of the salivary glands of each group in which AQP-5 was changed to red by setting the upper limit of the threshold to 100. By using magnified lightmicroscopic images twenty square territories of $200 \times$ $200 \mathrm{~mm}$ were randomly selected for each parotid and submandibular gland to calculate the numerical values of the area $\left(\mathrm{mm}^{2}\right)$ of AQP-5 in each territory. We conducted a statistical analysis of these numerical values between the normal mice and First stage (Short-term ad), between the First stage (Short-term ad) and Last stage (Long-term ad), between the First stage and Short-term ad, and between the Last stage and Longterm ad. A Mann-Whitney test (two-sided test) was used to confirm statistical differences between two groups. A value of $\mathrm{P}<0.05$ was considered to be statistically significant.

\section{RESULTS}

\section{1. $H \&$ E staining of the parotid, submandibular and sublingual glands of each group}

\section{1-a: Normal mice not ministered Cevimeline}

The structures of the salivary acinar cells and interlobular ducts were normal on H\&E staining, with no inflammation such as lymphocytic infiltrate around the interlobular ducts or blood vessels in any salivary glands (Figs. 2A-C).

\section{1-b: SS mice not administered Cevimeline}

In the First stage, inflammation was detected by
H\&E staining, such as slight lymphocytic infiltrate around the ducts or blood vessels, from the intercalated interlobular ducts to the striated ducts, in some the parotid and submandibular glands (Figs. 2D and E). Furthermore, in the Middle and Last stages, lymphocytic infiltrate progressed to the areas around every part of the interlobular duct or blood vessel in the parotid and submandibular glands, resulting in irregularly changed images of the acinar cells or ducts (Figs. $2 \mathrm{G}$ and $\mathrm{H}$ ). While no inflammation was observed in the sublingual glands in the First stage (Fig. 2F), mild lymphocytic infiltrate was found surrounding every part of the duct in the Middle and the Last stages, most likely as a result of aging (Fig. 2I).

\section{1-c: SS mice administered Cevimeline}

Similar morphological features in SS mice not administrated Cevimeline were revealed by H\&E staining - there were no differences in the progress or level of inflammation detected (Figs. 2J-O).

\section{1-d: SS mice discontinuing Cevimeline}

$\mathrm{H} \& \mathrm{E}$ staining found lymphocytic infiltrate surrounding the interlobular ducts and blood vessels, from the intercalated ducts to striated ducts in the parotid and submandibular glands of mice, at 2 weeks after discontinuation of Cevimeline. Irregular morphological changes of the acinar cells or ducts were observed in these mice. Furthermore, the lymphocytic infiltrate was aggravated in the parotid and submandibular glands in mice 4 weeks after discontinuing Cevimeline, thus allowing for the further progression of irregularities in the acinar cells or ducts (Figs. 2P and Q). Mild lymphocytic infiltrate was found surroundings all parts of the duct in the sublingual glands in mice that discontinued Cevimeline at both 2 and 4 weeks. Although some irregular ducts were detected, almost no morphological changes were found in the acinar cells (Fig. 2R).

\section{Immunohistochemical staining of AQP-5 in the pa- rotid, submandibular and sublingual glands of each group}

\section{2-a: Normal mice not administered Cevimeline}

Localization of AQP-5 was found mostly in the apical and sidewall membranes of the acinar cells, displaying an aster-like localization. However, localization of AQP-5 was observed in the basolateral membrane of the acinar cells of some parotid and submandibular glands (Figs. 3A and B) . Furthermore, no localization of AQP-5 was detected in the acinar cells of the sublingual glands (Fig. 3C) (Table 1). The 


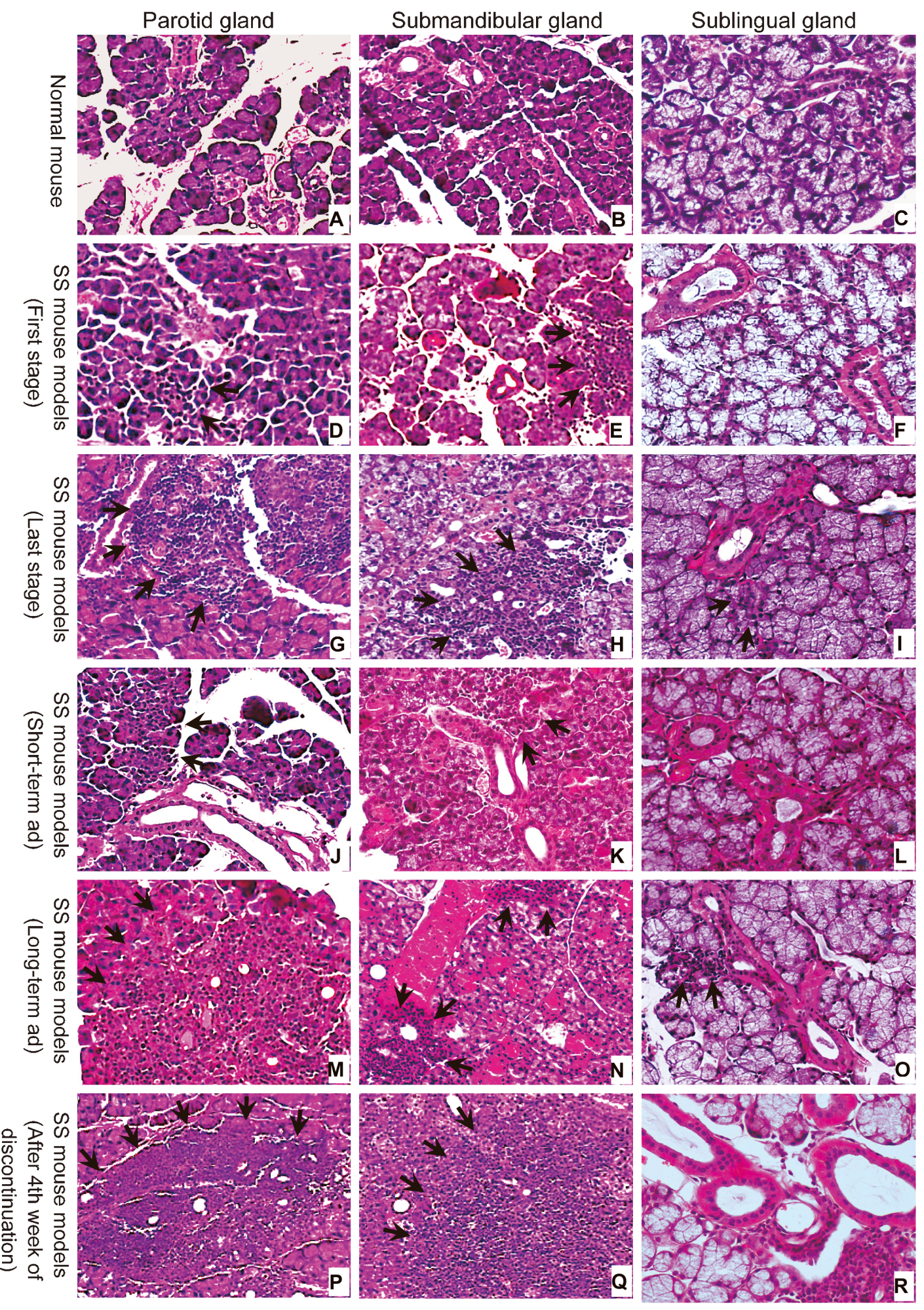

Fig. 2. H-E staining of the parotid glands, submandibular glands and sublingual glands of each group.

A-C: Normal mice, D-F: SS mouse models (First stage), G-I: SS mouse models (Last stage), J-L: SS mouse models (Short-term ad), M-O: SS mouse models (Long-term ad), P-R: SS mouse models (After 4th week of discountinuation)

Arrows: The Lymphocytic infiltration advanced around the interlobular ducts and blood vessels due to aging, regardless of administrated Cevimeline and non-administrated Cevimeline. $(A-R: \times 200)$ 
average calculated area of AQP-5 was $4150 \pm 1052$ $\mathrm{mm}^{2}$ for the parotid glands and $2096 \pm 585 \mathrm{~mm}^{2}$ for submandibular glands.

\section{2-b: SS mice not administered Cevimeline}

Localization of AQP-5 was found in the apical, sidewall and basolateral membranes of the acinar cells of most of the parotid glands and submandibular glands in the First stage (Figs. 3D and E) (Table 1). From the Middle to Last stage, a decrease in expression caused by aging was observed in the acinar cells of a large number of the parotid and submandibular glands (Figs. $3 \mathrm{G}$ and $\mathrm{H}$ ). No localization of AQP-5 was found in the acinar cells of the sublingual glands (Figs. $3 \mathrm{~F}$ and I) (Table 1). The average calculated area of AQP-5 was $3569 \pm 2372 \mathrm{~mm}^{2}$ for the parotid glands in the First stage and $1967 \pm 1652 \mathrm{~mm}^{2}$ for the parotid glands in the Last stage. For the submandibular glands, the average area of AQP-5 was $2487 \pm 1925 \mathrm{~mm}^{2}$ in the First stage and $580 \pm 433 \mathrm{~mm}^{2}$ in the Last stage. The difference in the expression levels of AQP-5 between the First and the Last stages was significant for the parotid glands $(\mathrm{P}=0.0398)$ and for the submandibular glands $(\mathrm{P}=0.00001)$, reflecting a significant decrease in AQP-5 expression in the Last stage compared with the First stage (Table 2). No significant difference was found in the expression levels of AQP-5 between normal and SS mice at the First stage for the parotid glands $(\mathrm{P}=0.4)$ or for the submandibular glands $(\mathrm{P}=0.74)$.

\section{2-c: SS mice administered Cevimeline}

Localization of AQP-5 was observed in most of the apical and sidewall membranes of the acinar cells of the parotid and submandibular glands, displaying an aster-like localization in the Short-term ad group. However, localization of AQP-5 was observed in the basolateral membrane of the acinar cells of some parotid and submandibular glands (Figs. 3J and K) (Table

TABLE 1

The localization of AQP-1, 3, 4, 5 and 8 in the parotid glands, submandibular glands and sublingual glands of each group

\begin{tabular}{|c|c|c|c|c|c|c|c|c|c|c|c|c|}
\hline \multirow[b]{3}{*}{$\begin{array}{l}\text { Locali- } \\
\text { zation } \\
\text { of AQP }\end{array}$} & \multicolumn{6}{|c|}{ Parotid glands \& Submandibular glands } & \multicolumn{6}{|c|}{ Sublingual glands } \\
\hline & \multirow[b]{2}{*}{$\begin{array}{l}\text { Myoepi- } \\
\text { thelial } \\
\text { Cells } \\
\text { (Cyto- } \\
\text { plasm } \\
\text { and } \\
\text { Mem- } \\
\text { branes) }\end{array}$} & \multirow[b]{2}{*}{$\begin{array}{l}\text { Vascular } \\
\text { endothe- } \\
\text { lial } \\
\text { cells }\end{array}$} & \multicolumn{3}{|c|}{ Acinar cells } & \multirow[b]{2}{*}{$\begin{array}{l}\text { Inter- } \\
\text { lobular } \\
\text { duct } \\
\text { (Cyto- } \\
\text { plasm } \\
\text { and } \\
\text { Mem- } \\
\text { branes) }\end{array}$} & \multirow[b]{2}{*}{$\begin{array}{l}\text { Myoep- } \\
\text { ithelial } \\
\text { Cells } \\
\text { (Cyto- } \\
\text { plasm } \\
\text { and } \\
\text { Mem- } \\
\text { branes) }\end{array}$} & \multirow[b]{2}{*}{$\begin{array}{l}\text { Vascular } \\
\text { endothe- } \\
\text { lial } \\
\text { cells } \\
\end{array}$} & \multicolumn{3}{|c|}{ Acinar cells } & \multirow[b]{2}{*}{$\begin{array}{l}\text { Inter- } \\
\text { lobular } \\
\text { duct } \\
\text { (Cyto- } \\
\text { plasm } \\
\text { and } \\
\text { Mem- } \\
\text { branes) }\end{array}$} \\
\hline & & & $\begin{array}{l}\text { Apical } \\
\text { and } \\
\text { sidewall } \\
\text { mem- } \\
\text { branes }\end{array}$ & $\begin{array}{l}\text { Basola- } \\
\text { teral } \\
\text { mem- } \\
\text { branes }\end{array}$ & $\begin{array}{l}\text { Cyto- } \\
\text { plasm }\end{array}$ & & & & $\begin{array}{l}\text { Apical } \\
\text { and } \\
\text { sidewall } \\
\text { mem- } \\
\text { branes }\end{array}$ & $\begin{array}{l}\text { Basola- } \\
\text { teral } \\
\text { mem- } \\
\text { branes }\end{array}$ & $\begin{array}{l}\text { Cyto- } \\
\text { plasm }\end{array}$ & \\
\hline AQP-1 & $\begin{array}{l}++ \\
+* \\
+* *\end{array}$ & $\begin{array}{l}++ \\
+* \\
+* *\end{array}$ & - & - & - & - & $\begin{array}{l}++ \\
+* \\
+* *\end{array}$ & $\begin{array}{l}++ \\
+* \\
+* *\end{array}$ & - & - & - & - \\
\hline AQP-3 & - & - & - & $\begin{array}{l}++ \\
+* \\
+* *\end{array}$ & - & $\begin{array}{l}++ \\
+* \\
+* *\end{array}$ & - & - & - & $\begin{array}{l}++ \\
+* \\
+* * \\
\end{array}$ & - & $\begin{array}{l}++ \\
+* \\
+* *\end{array}$ \\
\hline AQP-4 & - & - & - & $\begin{array}{l}++ \\
\pm * \\
\pm * *\end{array}$ & - & $\begin{array}{l}++ \\
\pm * \\
\pm * *\end{array}$ & - & - & - & $\begin{array}{l}+ \\
\pm * \\
\pm * *\end{array}$ & - & $\begin{array}{l}++ \\
\pm * \\
\pm * *\end{array}$ \\
\hline AQP-5 & - & - & $\begin{array}{l}++ \\
+* \\
+* *\end{array}$ & $\begin{array}{l} \pm \\
++* \\
\pm * *\end{array}$ & - & - & - & - & - & - & - & - \\
\hline AQP-8 & - & - & - & $\begin{array}{l}++ \\
+* \\
+* *\end{array}$ & - & $\begin{array}{l}++ \\
+* \\
+* *\end{array}$ & - & - & - & $\begin{array}{l}++ \\
+* \\
+* *\end{array}$ & - & $\begin{array}{l}++ \\
+* \\
+* *\end{array}$ \\
\hline
\end{tabular}

The localization of AQP-1, 3, 4 and 8 in the parotid glands, submandibular glands, sublingual glands of each group

This table expresses the common result of Normal mouse, SS mouse models* ( Non-administration of Cevimerine, First stage), and SS mouse models $* *$ (administration of Cevimerine, Short term ad).

Explanation of the sign $(++,+, \pm,-)$ of this table:

++ : Too much expression of AQPs

+: Many expression of AQPs,

\pm : Some expression of AQPs

-: No expression 


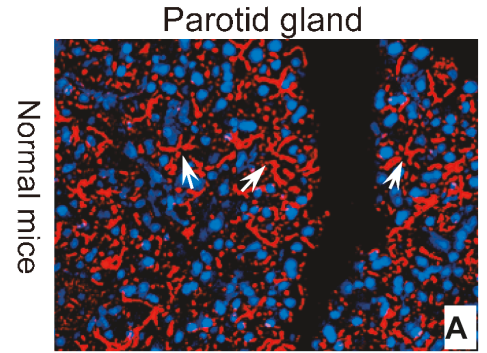

Submandibular gland

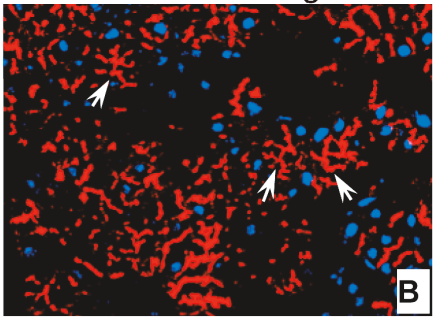

Sublingual gland
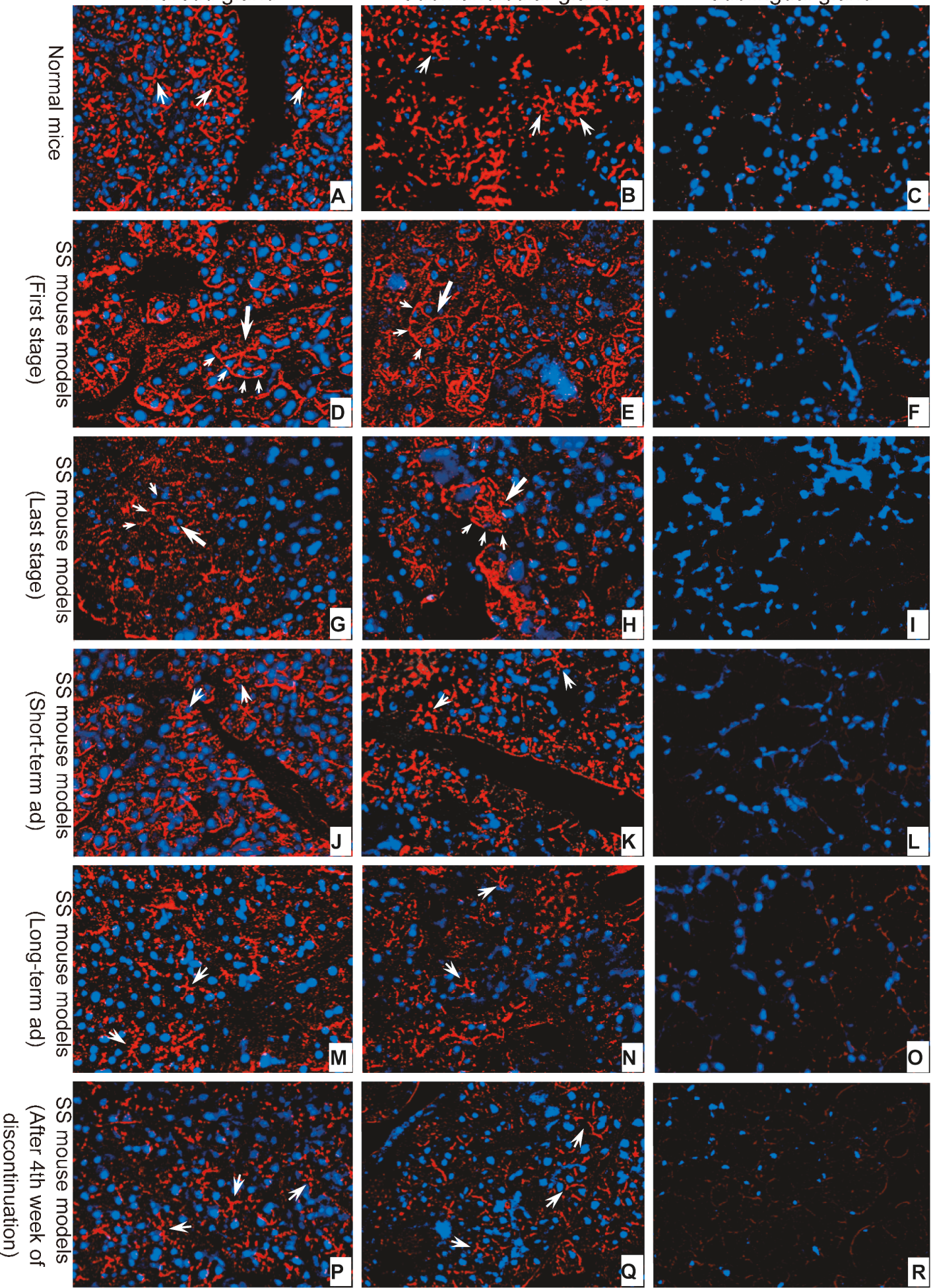

Fig. 3. Immunohistochemical staining of AQP-5 (Red area) in the parotid glands, submandibular glands and sublingual glands of each group.

A-C: Normal mice, D-F: SS mouse models (First stage), G-I: SS mouse models (Last stage), J-L: SS mouse models (Short-term ad), M-O: SS mouse models (Long-term ad), P-R: SS mouse models (After 4th week of discountinuation) AQP-5 of the acinar cells immunoreaction was observed in parotid glands and submandibular glands.

Big arrows: The apical membranes of the acinar cells, Small arrows: The basolateral membranes of the acinar cells, Blue area: nuclei (DAPI ), (A-F: $\times 200)$ 
1). Although the localization of AQP-5 of aster-like composition was observed in the acinar cells of most of the parotid and submandibular glands, in the Middleterm ad and Long-term ad groups, a decrease in expression was found in many acinar cells compared with those of the Short-term ad group (Figs. 3M and $\mathrm{N})$. No localization of AQP-5 was observed in the acinar cells of the sublingual glands (Figs. 3L and O) (Table 1). The average calculated area of AQP-5 for parotid glands was $2234 \pm 1123 \mathrm{~mm}^{2}$ in the Short-term $\mathrm{ad}$ and $1568 \pm 1138 \mathrm{~mm}^{2}$ in the Long- ad. For the submandibular glands, the average area for AQP-5 localization was $3417 \pm 1760 \mathrm{~mm}^{2}$ in the Short-term ad and $1364 \pm 1058 \mathrm{~mm}^{2}$ in the Long-term ad groups. Significant differences in the expression level of AQP-5 were found between Short-term ad and Longterm ad for the parotid glands $(\mathrm{P}=0.04248)$ and for the submandibular glands $(\mathrm{P}=0.00008)$, thus indicating a significant decrease in AQP-5 expression in Longterm ad compared with Short-term ad (Table 2).

\section{2-d: Statistical differences between the Cevime-} line-treated and untreated SS mice (Table 3)

The differences in the expression level of AQP-5 between the First stage and the Short-term ad were not significant for the parotid glands $(\mathrm{P}=0.08835)$ or for the submandibular glands $(\mathrm{P}=0.05146)$. Differences in the expression level of AQP-5 in the Last stage and the Long-term ad were not significant for the parotid glands $(\mathrm{P}=0.66515)$ but were significant for the submandibular glands $(\mathrm{P}=0.00319)$. Although no significant difference in the expression level of AQP-5 was found in the parotid glands, expression in the sub- mandibular glands was significantly lower in the Last stage compared with the Long-term ad group.

\section{2-e: SS mice discontinuing Cevimeline}

At two weeks after discontinuation, localization of AQP-5 was detected in the apical and sidewall membranes of most of the acinar cells of the parotid and submandibular glands, displaying an aster-like localization. However, localization of AQP-5 was observed in the basolateral membrane of some acinar cells. Furthermore, the localization of AQP-5 showed an aster-like localization even after the fourth week of discontinuation (Figs. 3P and Q). No localization of AQP-5 was observed in the acinar cells of the sublingual glands including the ducts (Fig. 3R).

\section{Immunohistochemical staining of $A Q P-1,3,4,8$ in the parotid, submandibular and sublingualglands of each group}

\section{3-a: Normal mice not administered Cevimeline}

The localization of AQP-1 was observed in the myoepithelial cell membranes and cytoplasm, and a large number of capillaries and small vessels (arterioles and venules) of the parotid, submandibular and sublingual glands (Figs. 4A-C).

The localization of AQP-3 was observed in the basolateral membrane of the acinar cells of some parotid, submandibular and sublingual glands, and in almost all duct membranes and duct cytoplasm, from intercalated ducts to striated ducts (Figs. 4D-F).

The localization of AQP-4 was observed in some basolateral membranes of the acinar cells of some pa-

TABLE 2.

The statistical difference of the expression levels of AQP-5 due to aging

\begin{tabular}{|c|c|c|c|c|c|c|}
\hline Salivary glands & First stage & Last stage & $\begin{array}{c}\text { First stage vs. Last } \\
\text { stage }(\mathrm{P})\end{array}$ & Short-term ad & Long-term ad & $\begin{array}{l}\text { Short-term ad vs. } \\
\text { Long-term ad (P) }\end{array}$ \\
\hline Parotid glands & $3569 \pm 4744 \mathrm{~mm}^{2}$ & $1967 \pm 3304 \mathrm{~mm}^{2}$ & $0.0398(\mathrm{P}<0.05)$ & $2234 \pm 2247 \mathrm{~mm}^{2}$ & $1568 \pm 2277 \mathrm{~mm}^{2}$ & $0.0424(\mathrm{P}<0.05)$ \\
\hline Submandibular glands & $2487 \pm 3851 \mathrm{~mm}^{2}$ & $580 \pm 866 \mathrm{~mm}^{2}$ & $0.00001(\mathrm{P}<0.05)$ & $3417 \pm 3520 \mathrm{~mm}^{2}$ & $1364 \pm 2117 \mathrm{~mm}^{2}$ & $0.00008(\mathrm{P}<0.05)$ \\
\hline
\end{tabular}

TABLE 3.

The statistical difference of between the Cevimeline-treated and untreated SS mice

\begin{tabular}{|c|c|c|c|c|c|c|}
\hline Salivary glands & First stage & Short-term ad & $\begin{array}{l}\text { First stage vs. } \\
\text { Short-term ad (P) }\end{array}$ & Last stage & Long-term ad & $\begin{array}{l}\text { Last stage vs. } \\
\text { Long-term ad (P) }\end{array}$ \\
\hline Parotid glands & $3569 \pm 4744 \mathrm{~mm}^{2}$ & $2234 \pm 2247 \mathrm{~mm}^{2}$ & $0.08835(\mathrm{P}>0.05)$ & $1967 \pm 3304 \mathrm{~mm}^{2}$ & $1568 \pm 2277 \mathrm{~mm}^{2}$ & $0.66515(\mathrm{P}>0.05)$ \\
\hline Submandibular glands & $2487 \pm 3851 \mathrm{~mm}^{2}$ & $3417 \pm 3520 \mathrm{~mm}^{2}$ & $0.05146(\mathrm{P}>0.05)$ & $580 \pm 866 \mathrm{~mm}^{2}$ & $1364 \pm 2117 \mathrm{~mm}^{2}$ & $0.00319(\mathrm{P}<0.05)$ \\
\hline
\end{tabular}




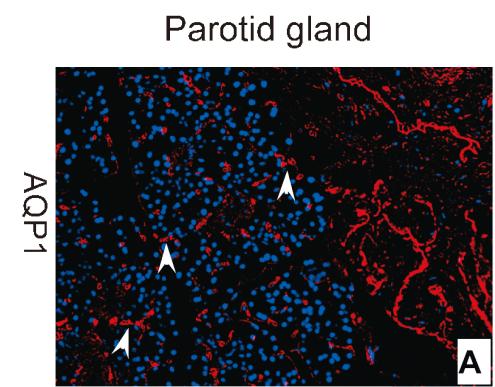

Submandibular gland
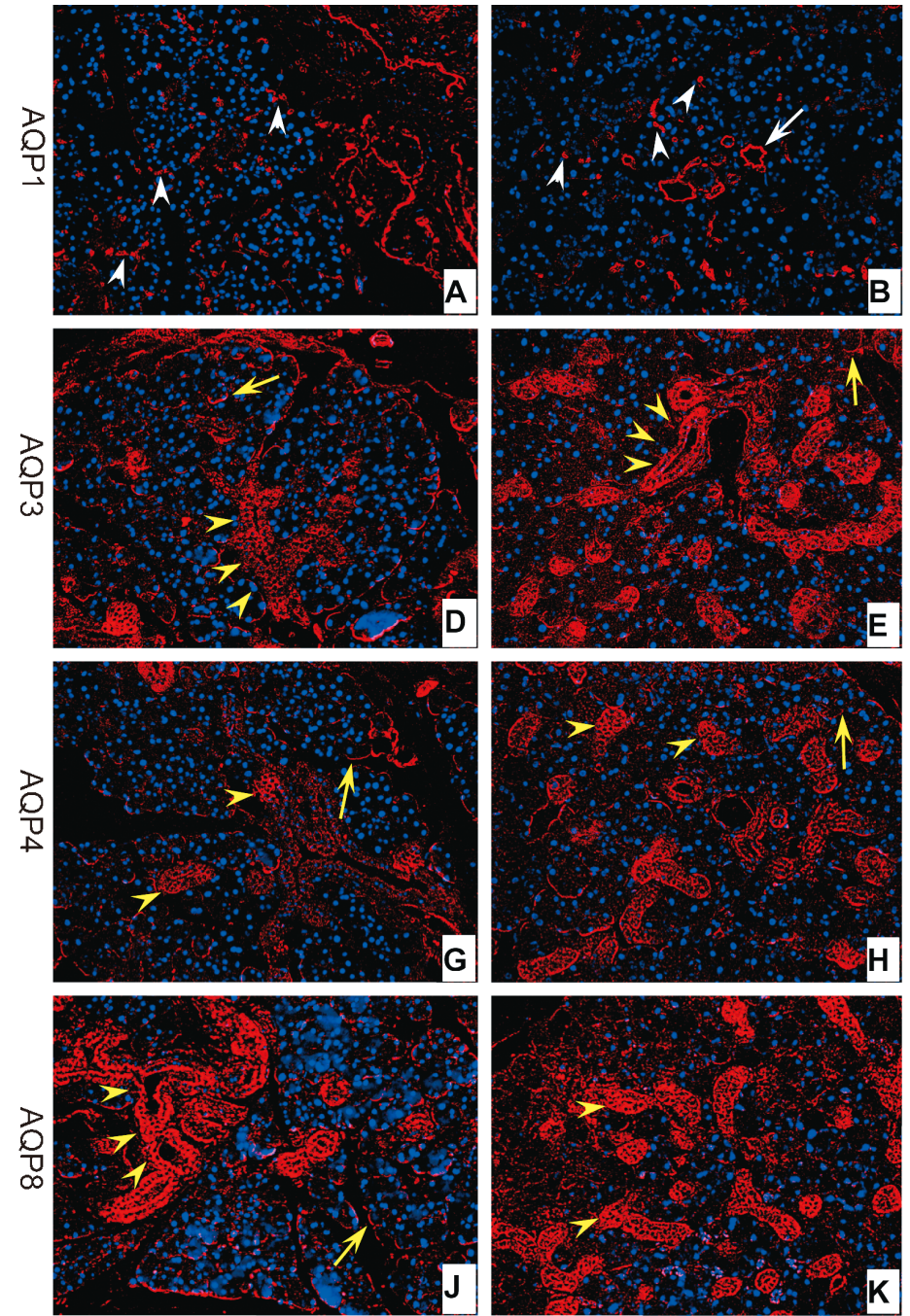

Sublingual gland
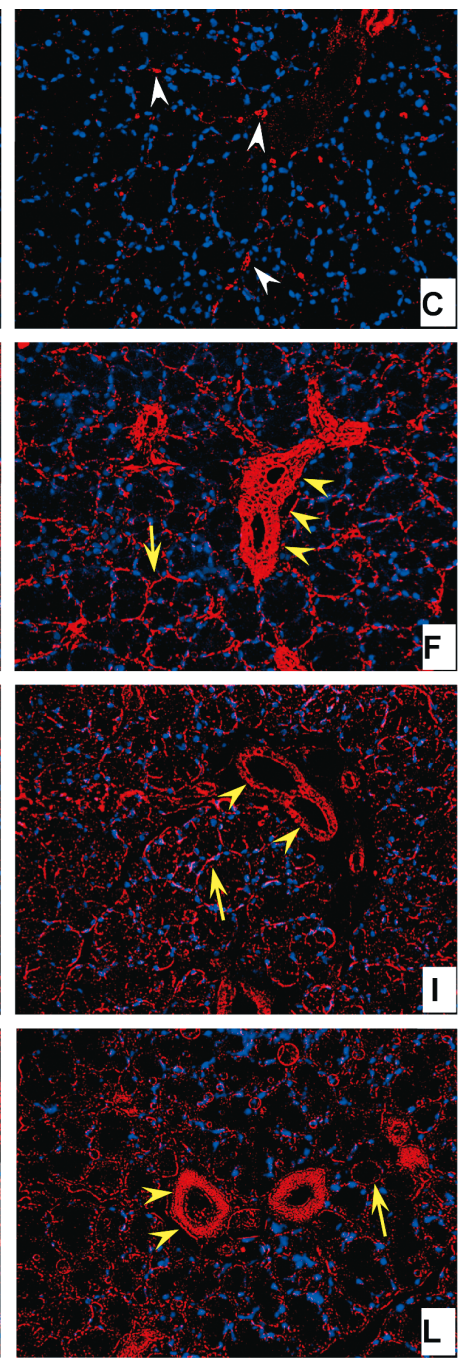

Fig. 4. Immunohistochemical staining of AQP-1, 3, 4 and 8 in the parotid glands, submandibular glands and sublingual glands of Normal mice.

Immunopositive area is red, nuclei is blue.

A-C: AQP-1 (White arrows: Myoepitherial cells, White arrow-heads: Vascular endothelial cells), D-F: AQP-3 ( Yellow arrows: Basolateral membranes, Yellow arrow-heads: Duct membranes and duct cytoplasm of parotid glands, submandibular glands and sublingual glands), G-I: AQP-4 (Yellow arrows and yellow arrow-heads: The same part as expression of AQP-3), J-L: AQP-8 (Yellow arrows and yellow arrow-heads: The same part as expression of AQP-3), (A-L: $\times 100)$

rotid, submandibular and sublingual glands, and in almost all regions of the duct membranes (Figs. 4G-I).

The localization of AQP-8 was observed in the basolateral membrane of the acinar cells of some parotid, submandibular and sublingual glands, and in almost all regions of the duct membranes and cytoplasm (Figs. 4J-L).

\section{3-b: Cevimeline-treated (Figs. 5, 6) and untreat- ed SS mice}

AQP-1 localization was observed, similar to nor- mal mice, in the myoepithelial cell membranes, cytoplasm, and a large number of vascular endothelial cell membranes of the capillaries and small vessels of many parotid, submandibular and sublingual glands in the Short-term ad (First stage) (Figs. 5A-C). However, the expression level of AQP-1 in the Short-term ad group was slightly weaker compared with that of normal mice. A mild decrease in expression due to aging was found in all myoepithelial and vascular endothelial cells of the parotid and submandibular glands in the Middle-term ad (Middle stage) and Long-term ad (Last 

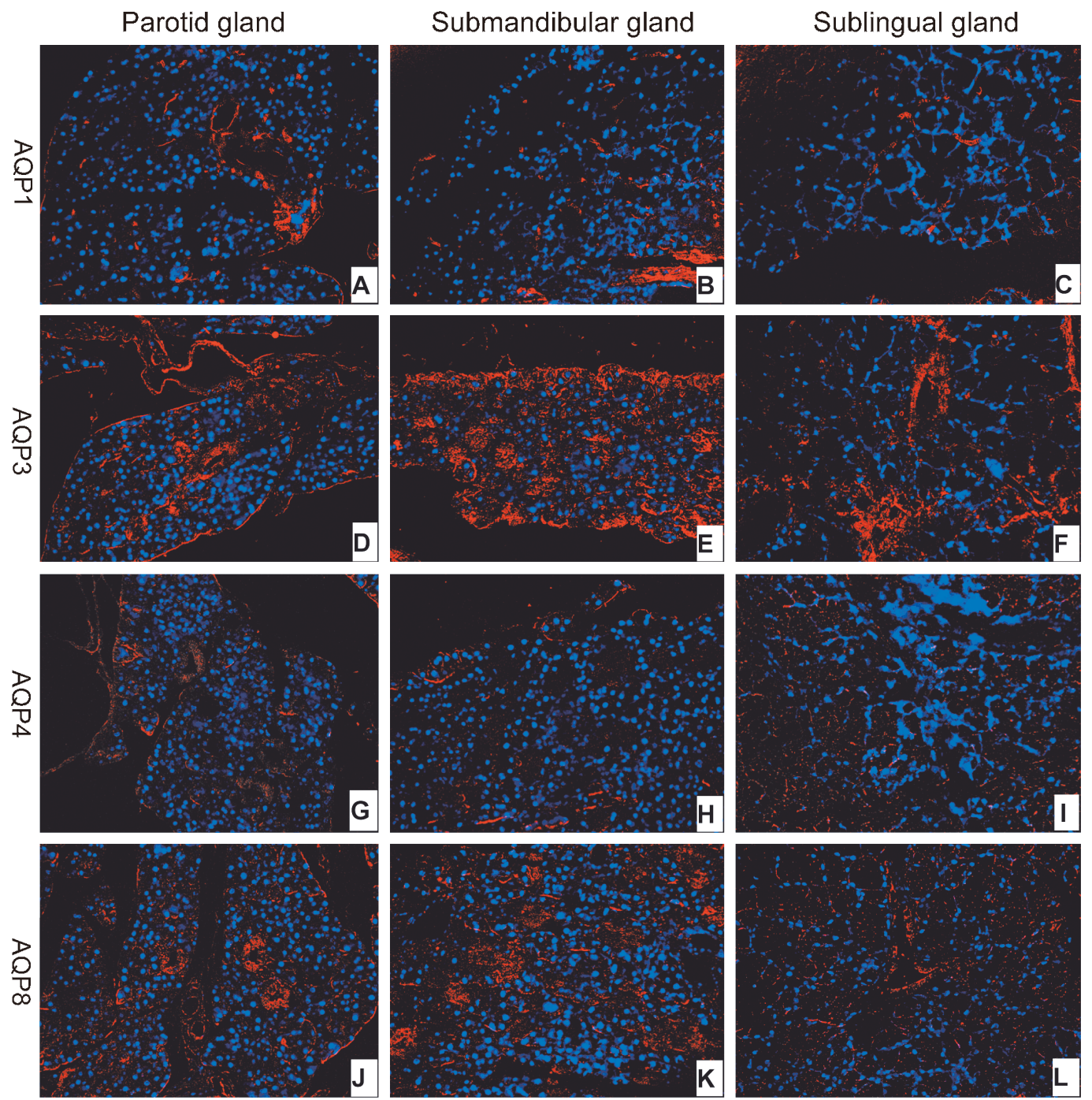

Fig. 5. Immunohistochemical staining of AQP-1, 3, 4 and 8 in the parotid glands, submandibular glands and sublingual glands in short-term ad ( 3 to 5 weeks after administration).

Immunopositive area is red, nuclei is blue.

A-C: AQP-1, D-F: AQP-3, G-I: AQP-4, J-L: AQP-8, (A-L: ×100)

stage) (Figs. 6A-C).

AQP-3, 4 and 8 localization was observed, similar to normal mice, in the basolateral membrane of the acinar cells of some parotid, submandibular and sublingual glands, and almost all duct membranes and duct cytoplasm in the Short-term ad (First stage) (Figs. 5DL). However, the expression level of AQP-3, 4 and 8 in the Short-term ad (First stage) was slightly weaker compared with normal mice. A mild decrease in expression due to aging was found in AQP-3, 4 and 8 in all acinar cells and all regions of the duct of the parotid and submandibular glands, in the Middle-term ad (Middle stage) and the Long-term ad (Last stage) (Figs. 6D-L). Furthermore, the expression level of AQP-4 was slightly weaker at all expression sites of the parotid, submandibular and sublingual glands, compared with those of AQP-1, 3 and 8.

\section{DISCUSSION}

This study investigated the effects of Cevimeline on the localization of AQP-5, which is related to saliva secretion. We compared groups of normal mice, Cevimeline-treated and untreated SS mice, and SS mice in which Cevimeline was administered and then discontinued. The effect on saliva secretion continued even with chronically administered Cevimeline, and these effects continued for at least 4 weeks after 

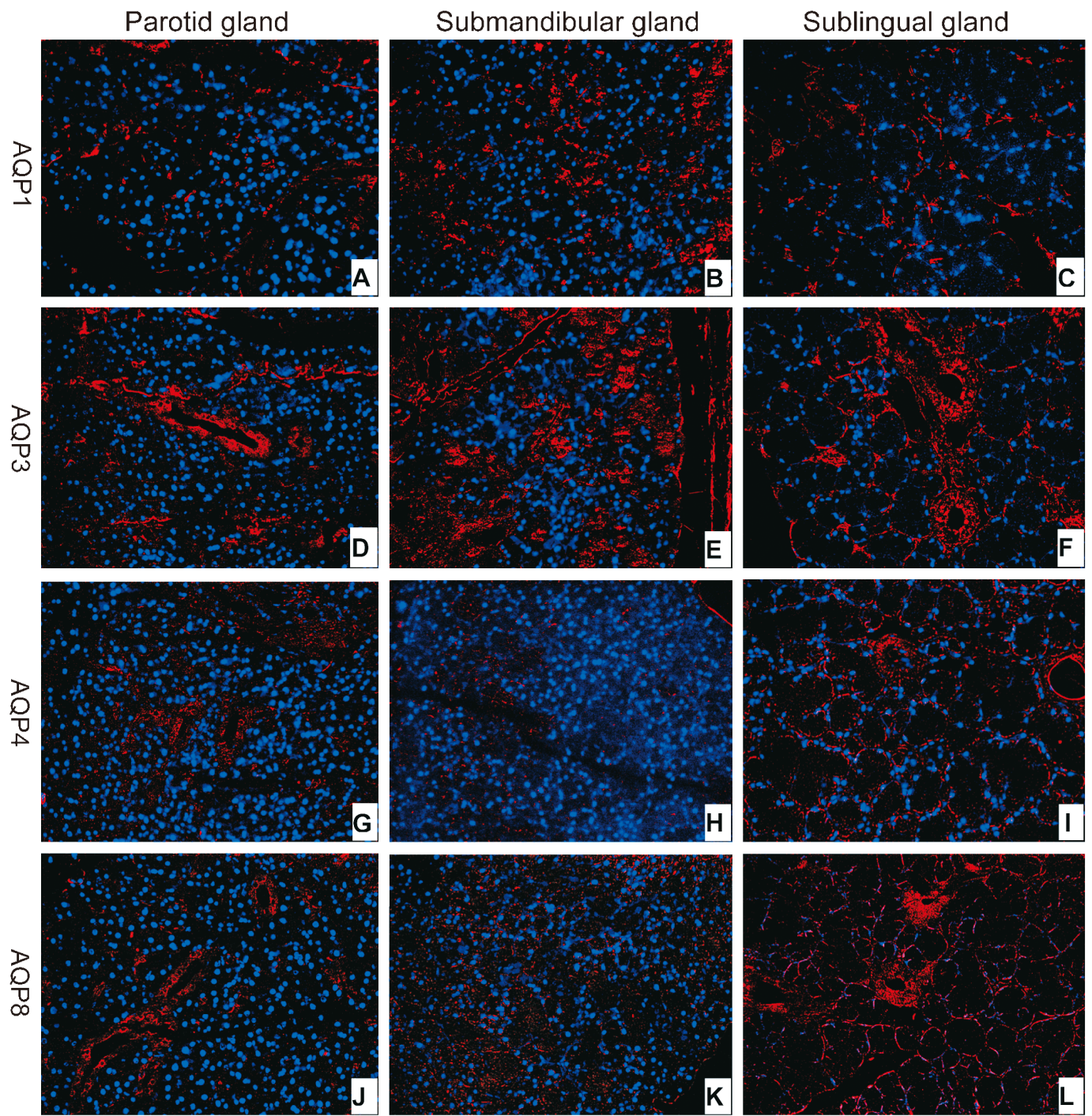

Fig. 6. Immunohistochemical staining of AQP-1, 3, 4 and 8 in the parotid glands, submandibular glands and sublingual glands in long-term ad (11 to 13 weeks after administration).

Immunopositive area is red, nuclei is blue.

A-C: AQP-1, D-F: AQP-3, G-I: AQP-4, J-L: AQP-8, (A-L: ×100)

Cevimeline discontinuation.

The MRL/l mice (SS mice) used in this study were those with autoimmune disorders that naturally develop symptoms of sialadenitis or angiitis, and exhibit lymphocytic infiltrate around the ducts and blood vessels due to aging [15-18].

Inflammation progressed at almost the same speed in SS mice administered Cevimeline as in those without administration. Lymphocytic infiltrate around the interlobular ducts and blood vessels was found in the First stage (Short-term ad). A large amount of lymphocytic infiltrate was also widely found due to aging in the Middle stage (Middle-term ad) and Last stage (Long-term ad). There was no significant difference in this inflammation between the parotid and submandibular glands, because the lymphocytic infiltrate progressed almost simultaneously. Furthermore, no inflammation of the sublingual glands was observed in the First stage. Very mild lymphocytic infiltrate was found around the interlobular ducts in the Middle and Last stage of the sublingual glands, most likely because of aging. Since no clear differences were found between Cevimeline administration and non-administration groups, we believe that Cevimeline did not affect sialadenitis, and invasion of the salivary gland tissues would be minimal even with chronic use.

AQP-5 is localized, at the time of saliva secretion, from the apical to the sidewall membrane of acinar 
cells of the salivary glands in normal mice. However, mislocalization occurs in the salivary acinar cells (small salivary or submandibular glands) of SS patients and SS mice [7, 19]. Yakeishi et al. suggested that the mislocalization of AQP-5 in the submandibular glands is improved by the oral administration of Cevimeline to SS mice [7]. We found that after chronic Cevimeline-treatment of mice in this study, the localization of AQP-5 was maintained from the apical to the sidewall membrane of the acinar cells in the parotid and submandibular glands. These results confirm previous findings that chronic administration of Cevimeline has an effect on saliva secretion. Since no mislocalization of AQP-5 occurred, even in SS mice after discontinuation of Cevimeline, we believe these results support the hypothesis that SS patients taking Cevimeline orally can increase saliva secretion even 2-4 weeks after discontinuation.

Significant differences were found in the expression levels of AQP-5 because of aging, (in the parotid and submandibular glands), in both Cevimeline-treated and untreated SS mice. This is because of the progressive nature of the inflammatory destruction of salivary gland organization in SS. Even though Cevimeline does not have an anti-inflammatory effect, we believe it continues acting on salivary acinar cells because the localization of AQP-5 maintains an aster-like localization even in the Long-term ad. Furthermore, comparing the expression levels of AQP-5 in the parotid and submandibular glands with or without the administration of Cevimeline, the expression levels of AQP-5 in the submandibular glands in the Last stage and the Long-term ad was significantly lower than levels in the Last stage. No significant differences were found in any other comparisons. We believe that chronic administration of Cevimeline enhanced the visualization of AQP- 5 because the localization of AQP-5 in the salivary acinar cells was maintained in the aster-like configuration. This resulted in a significant increase in the apparent expression level of AQP-5.

Next, we considered the localization of AQP-1, 3, 4 and 8 in the salivary glands from each group, and confirmed that AQP-3, 4 and 8 is localized in the basolateral membranes of acinar cells and inter lobular ducts in normal and Cevimeline-treated and untreated SS mice. Because AQP-3, 4, and 8 were not localized in the apical or sidewall membranes of the acinar cells in the salivary glands, they were not directly involved in saliva secretion. However, we believe that they may be indirectly involved in saliva secretion, specifically by promoting water transport into the salivary acinar cells and the re-absorption of water in the ducts. AQP-1 is localized in the membranes of vascular endothelial and myoepithelial cells and in the cytoplasm of myoepithelial cells, which have high membrane water permeability. It has been reported that they assist with water transport by surrounding the salivary acinar cells in a basket-like manner [20]. It has been reported that expression of AQP-1 in the salivary glands of SS patients is reduced by $38 \%$ [21], thus suggesting that AQP-1 also plays an important role in saliva composition.

We also confirmed that the mislocalization of AQP-5 is improved over longer periods of time by chronic administration of Cevimeline to SS mice. However, no localization changes for AQP-1, 3, 4 and 8 were observed with Cevimeline administration. It is believed that AQP-1, 3, 4 and 8 play a role in transferring the water required for saliva from the basolateral membranes of the acinar cells. Therefore, they were not directly involved in saliva secretion into the inside of the ducts. It is believed that the effects of Cevimeline on saliva secretion are due to its effect on the osmotic pressure gradient of the apical membrane of the acinar cells. As a result, no effects were found for AQP-1, 3, 4 and 8 as they are only localized on the basolateral membrane of these cells. However, we believe that steroidal anti-inflammatory drugs that have inhibitory action against the inflammatory destruction of salivary acinar cells will be useful to protect water channels that work indirectly on saliva secretions. Furthermore, their concomitant use with Cevimeline, which is involved in regulating AQP-5 is considered to be more effective than using either drug alone.

This study showed that sustainable salivary secretion, even with the chronic administration of Cevimeline, was achieved in SS mice. The results also show that saliva secretion continued for 2 to 4 weeks after discontinuation of Cevimeline. We confirmed that the chronic administration of Cevimeline has almost no side effects on salivary glands. Although the decrease in the amount of saliva secretion in SS mice may be due to the progressive inflammatory destruction of the salivary gland organization, we believe that the mislocalization of AQP-5 can be improved and the saliva secretory function can be sustained for longer periods of time with chronic Cevimeline treatment.

\section{REFERENCES}

1. Nakamura $\mathrm{S}$. The actual condition of medical examination: drymouth. Jpn J Clinical and Experimental Medicine 2007; 84:939-946. (in Japanese)

2. Akizuki M. Sjögren's syndrome. Jpn Med J 1992; 3542:3034. (in Japanese) 
3. Arisawa H, Imai E, Fujise N, Fukui K, and Masunaga H. General pharmacological profile of the novel muscarinic receptor agonist SNI-2011, a drug for xerostomia in Sjögren's syndrome. Arzneim.-Forsch./Drug Res 2002; 52:14-20.

4. Kashiwazaki S, Ichikawa Y, Torikai K, Kondo H, Miyawaki S et al. Examination of the dose increase method about the effectiveness and the safety of SNI-2011 against drymouth in sjögren's syndrome patients. Med Consult New Remedies 2001; 38:313-332. (in Japanese).

5. Ichikawa Y, Kashiwazaki S, Hara M, Torikai K, Kondo H et al. Double-blind test competitive examination between SNI-2011 and placebo against drymouth in sjögren's syndrome patients. Med Consultation and New Remedies 2001; 38:349-368. (in Japanese).

6. Iwabuchi H, Iwabuchi E, Uchiyama K, and Fujibayashi T. A study of ultra-long-term administration of cevimeline hydrochloride in patients with xerostomia due to sjögren's syndrome. J Jpn Oral Muco Membr 2010; 16:33-39. (in Japanese).

7. Yakeishi A. Fine structure of submandibular glands and immunolocalization of aquaporin-5 in sjögren's syndrome model mice after administration cevimeline. J Kurume Med Assoc 2008; 71:27-37. (in Japanese)

8. Agre P, Saboori AM, Asimos A and Smith BL. Purification and partial characterization of the $\mathrm{Mr} 30,000$ integral membrane protein associated with the erythrocyte Rh (D) antigen. J Biol Chem 1987; 262:17497-17503.

9. Preston GM, Carroll TP, Guggino WB and Agre P. Appearance of water channels in Xenopus oocytes expressing red cell CHIP28 protein. Science 1992; 256:385-387.

10. Raina S, Preston GM, Guggino WB and Agre P. Molecular cloning and characterization of an aquaporin cDNA from salivary, lacrimal, and respiratory tissues. J Biol Chem 1995; 270:1908-1912.

11. Matuzaki T, Suzuki T, Koyama H, Tanaka S and Takata K. Aquaporin-5 (AQP5), a water channel protein, in the rat salivary and lacrimal glands. Cell Tissue Res 1999;
295:513-521.

12. Akamatu T, Parvin MN, Murdiastuti K, Tanaka C, Yao C et al. Expression and localization of aquaporins, members of the water channel family, during development of the rat submandibular gland. Eur J Physiol 2003; 446:641-651.

13. Ma T, Song Y, Gillespie A, Carlson EJ, Epstein CJ et al. Defective secretion of saliva in transgenic mice lacking aquaporin-5 water channels. J Biol Chem 1999; 274:2007120074.

14. Krane CM, Melvin JE, Nguyen HV, Richardson L, Towne $\mathrm{JE}$ et al. Salivary acinar cells from aquaporin 5-deficient mice have decreased membrane water permeability and altered cell volume regulation. J Biol Chem 2001; 276:23413-23420.

15. Hayashi Y, Haneji N and Hamano H. Pathogenesis of sjögren's syndrome-like autoimmune lesions in MRL/lpr mice. Pathol Int 1994; 44:559-568.

16. Hoffman RW, Alspaugh MA, Waggie KS, Durham JB, Walker SE et al. Sjögren's syndrome in MRL/l and MRL/n mice. Arthritis Rheum 1984; 27:157-165.

17. Tanaka A, O’Sullivan FX, Koopman WJ and Gay S. Ultrastructural study of sjögren's syndrome-like disease in MRL/1 mice. J Oral Pathol 1988; 17:460-465.

18. Cutler LS, Bullis D, Christian CP, Rendell JR and Greiner DL. Animal models of sjögren's syndrome. J Dent Res 1987; 66:590-591.

19. Steinfeld S, Cogan E, King LS, Agre P, Kiss R et al. Abnormal distribution of aquaporin-5 water channel protein in salivary glands from sjögren's syndrome patients. Lab Invest 2001; 81:143-148.

20. Gresz V, Kwon TH, Hurley PT, Varga G, Zelles T et al. Identification and localization of aquaporin water channels in human salivary glands. Am J Physiol 2001; 281:247254.

21. Beroukas D, Hiscock J, Gannon BJ, Jonssson R, Gordon $\mathrm{TP}$ et al. Selective down-regulation of aquaporin-1 in salivary glands in primary sjögren's syndrome. Lab Invest 2002; 82:1547-1552. 